\title{
Cultivating Resilience and Self-control among University Students: An Experimental Study
}

\author{
Renee Morrison", Aileen M. Pidgeon \\ School of Psychology, Bond University, Australia
}

Copyright $\subset 2017$ by authors, all rights reserved. Authors agree that this article remains permanently open access under the terms of the Creative Commons Attribution License 4.0 International License

\begin{abstract}
University Students report a range of demands such as academic responsibilities, financial pressures or developing new social networks to be major sources of stress. The literature demonstrates that university students report higher levels of psychological distress compared to the general population. Therefore, the cultivation of resilience and self-control among university students could result in many benefits. Resilience is the ability to adapt successfully to stress and adversity, while self-control is the ability to resist short-term desires in order to meet long-term goals. This experimental study examined the efficacy of using brief willpower strengthening exercises to enhance resilience, self-control, and reduce psychological distress in university students. Forty-six university students were randomised into one of two groups: Willpower Strengthening Group or the Control Group. A two-way repeated MANOVA revealed that university students in the Willpower Strengthening Group reported significantly higher levels of resilience and self-control, and significantly lower levels of psychological distress. The positive feedback and high rate of compliance reported by students to the exercises as per instructions (i.e. every hour, for six hours per day, over seven days) supports the feasibility of using willpower strengthening exercises in programs aimed at increasing resilience. Future research into the feasibility and effectiveness of willpower strengthening exercises has the potential to improve the psychological wellbeing of university students.
\end{abstract}

Keywords Randomised Controlled Trial, Willpower, Self-control, Resilience, Psychological Distress

\section{Introduction}

Australian university students report higher levels of psychological distress compared to the general population [1]. Some students fail to reach their academic potential because they do not possess the coping skills to overcome the challenges and adversity of university life [2]. Students who demonstrate the capacity to cope effectively with stress relating to university pressures have been shown to report more resilient characteristics [3]. Therefore, the cultivation of resilience among university students is important.

Resilience has been identified as a key factor of psychological well-being [4]. However, few studies have investigated how resilience can be cultivated and enhanced among university students. It has been identified that self-control is a key psychological factor associated with the cultivation of resilience $[5,6]$. The Strength Model of Self-Control postulates that regularly exercising self-control can improve willpower strength, analogous to the way exercise can improve muscle strength $[7,8]$. The aim of this present study was to evaluate the efficacy and feasibility of willpower strengthening exercises on cultivating resilience and self-control, whilst reducing psychological distress among university students.

Resilience is defined as a "personality characteristic that moderates the negative effects of stress and promotes adaptation" [9]. Wagnild and Young used ground theory to identify five underlying characteristics of resilience, these include: a purposeful life, perseverance, equanimity, self-reliance, and existential aloneness [10]. For the purposes of this study, only perseverance and self-reliance were measured as they are two key components that underlie self-control [11].

Self-control is an important factor linked to the cultivation and enhancement of resilience and the reduction of psychological distress [12]. For example, Ayduk, Mendoza-Denton, Mischel, and Downey [14, 15] highlighted that effective self-control strategies in childhood relate to resiliency later in life. Individuals high in self-control may be more resilient to adversity because they are better at using cognitive reappraisal strategies that transform the subjective meaning of a threatening situation to make it less threatening [13].

University students who experience psychological distress report lower levels of resilience, poorer relationships with peers, greater adjustment issues, and higher dropout rates [17, 18]. Furthermore, DeRosier, Frank, Schwartz, and Leary [19] investigated the resilient factors related to individual stress 
responses. The results showed that students who reported higher levels of resilience also reported higher self-esteem and the ability to engage in adaptive behaviours requiring self-control for positive mental health and well-being.

Self-control is defined as the capacity to override or change cognitive, emotional and behavioural responses [7, 12]. According to Baumeister and Colleagues [10] there are five domains of self-control: thought control, emotional control, impulse control, performance regulation, and habit breaking. The first domain is thought control is the ability to effectively regulate your own cognitive processes. It is common for individuals to experience increased cognitive errors and biases under stress, as the ability to effectively regulate cognition is diminished [20]. The second domain is emotional control and refers to the regulation of feelings, emotions and mood [21]. It consists of a range of complex processes that involves monitoring, assessing, and altering internal emotional processes [12]. The ability to effectively regulate emotions is strongly associated with enhanced psychological well-being and resilience $[22,23]$.

Impulse control is the third domain and is the ability to override urges, such as cravings or longings to do a particular thing, such as smoke, gamble, or drink [28]. An impulse control is a specific motivation or desire to perform a particular action, as opposed to a latent desire or trait. For example, the feeling of hunger is not an impulse, but a feeling of wanting to have a piece of cake is an impulse. The fourth domain is performance control, which is the capacity to regulate one's behaviours in order to achieve goals (for example, academic or occupational).

Baumeister and Colleagues [7] suggested that willpower is vulnerable to "ego depletion" over time from repeated exertion-similar to the way a muscle gets tired from exercise. The term "willpower" as a metaphor for self-control has long been used in psychology literature. Freud [24] originally proposed that volition was based on the ego that required a type of limited energy resource to gain its goals and resist the desires of the id and superego. The term "ego depletion" pays homage to Freudian theory, which states that an inner resource diminishes after the exertion of self-control.

Baumeister, Bratslavsky, Muraven, and Tice [25] tested the hypothesis that acts of self-control draw on a limited resource, similar to a strength or energy. University students $(\mathrm{N}=67)$ were randomly assigned to either eat a chocolate or eat a radish condition. Participants were presented with a bowl of chocolate chip cookies and another bowl that consisted of red and white radishes. They were then asked to take 5 minutes to taste the assigned food while the researchers left the room. When researchers returned to the laboratory, participants completed a problem-solving task. Participants assigned to the no-food control group skipped the food part of the experiment and went directly to the problem-solving exercise. The problem solving was presented as if it was unrelated to the eating, but was in fact it was the main dependent measure.

Results revealed that participants in the radish condition stopped the problem-solving task sooner than participants in the chocolate condition or the no-food condition. The chocolate condition did not differ from the no-food condition. This outcome provided preliminary support for the ego depletion hypothesis.

A limitation of the study was the lacks of generalisibility to all domains of self-control as only impulse and performance control were measured. As a result, the inferences that can be made about the nature of ego depletion from the study are limited. This present study addresses this limitation by evaluating the effects of willpower strengthening exercises across five self-control domains, these include: emotional control, thought control, performance control, impulse control, and habit breaking [26].

The Strength Model of Self-Control proposes that self-control is similar in function to that of a muscle and therefore should become stronger with exercise [7, 10]. Muraven, Baumeister, and Tice [35] investigated this hypothesis with university students $(\mathrm{N}=69)$ using an experimental design. Participants were instructed to maintain their grasp on a handgrip, which is tiring for hand muscles made participants want to eventually relax them. The amount of time a participant was able to resist relaxing their hand was the baseline measure of self-control. Participants then completed the five-minute "white bear" thought suppression task [26]. After the thought suppression task researchers took a second measure of self-control was taken again, using the handgrip measure.

Researchers then assigned participants to the one of five self-control exercise groups for the next 2 weeks. A no-effort control group was included and given no instruction for the proceeding 2 weeks. When participants returned to the laboratory at the end of the 2 weeks for the post-test session, the hand-grip and thought suppression task were performed again in the exact same way at pre-test. Results revealed that in comparison to the control group, participants in the four groups showed a smaller decline in performance following the thought suppression exercise at post-test. Similar to previous research by Baumeister and Colleagues [10] measured only ego depletion in terms of performance control. Further, the self-control exercises were not standardised across participants, for example, participants were told to adjust their posture when they "remembered to do so". Furthermore, the measure of compliance was based on participants retuning their diary at the end of the study, as opposed to whether the participants actually recorded carrying out the assigned tasks. This present study addressed these limitations by standardising self-control exercises to ensure consistency across participants.

Previous research conducted by Muraven and Colleagues [10] utilised a self-control exercises intervention over a two-week period, which showed significant improvements in willpower strength. The present study evaluated the effectiveness of willpower strengthening exercises over a seven-day intervention. The rationale for using an intensive, short-term approach to strengthen willpower was to increase 
both recruitment and compliance to complete the allocated exercises, as well as to reduce attrition rates from the study due to the high work-load and time constraints placed on students. Components of the self-control exercises used in this current study were based on interventions used in previous research $[10,12]$. The exercises involved participants correcting their posture, then briefly acknowledging the thoughts feelings, emotions they noticed. To the researchers' knowledge this is the first study to measure the effectiveness of willpower strengthening exercises across five-domains of self-control. On the basis of research presented it is hypothesised that the willpower strengthening group will report significantly higher levels of self-control and resilience, and significantly lower levels of psychological distress compared to the control group at post-intervention. In addition, it is predicted that the feasibility of willpower strengthening exercises with university students will be supported.

\section{Materials and Methods}

\subsection{Participants}

A sample of 46 undergraduate students participated in this study. The participant's age range was 18 to 35 years of age $(M=26.24, S D=7.65)$. The sample was comprised of 36 females $(78 \%)$ and ten males $(22 \%)$.

\subsection{Brief-self Control Scale (BSCS) [32]}

The BSCS assess behavioural self-control in individuals of an unspecified age group. The BSCS is a 13-item, five-factor, self-report questionnaire. The five factors of the BSCS are cognitive control, emotional control, impulse control, performance regulation, and habit breaking. Items are rated on a 5-point Likert scale, ranging from 1 (not at all like me) to 5 (very much like me). Total scores are calculated by adding all the items scores, giving potential rating of 13 to 65 . Higher scores indicate greater self-control. The internal consistency $(\alpha=.85)$ showed adequate intercorrelations between scale items [33, 34].

\subsection{The Resilience Scale (RS) [35]}

The RS is a 25 -item scale that measures five factors of resilience, these include: equanimity, perseverance, self-reliance, meaningfulness and existential loneness. For the purposes of this study the perseverance ("When I make plans, I follow through with them.") and self-reliance ("I usually manage one way or another") scales were measured. Participants indicate on a 7-point Likert scale, ranging from 1 (Disagree) to 7 (Agree). The internal consistency of the RS was adequate $(\mathrm{r}=.91)$. Item-to-total correlations ranged from .37 to .75 with the majority falling within the range of .50 to .70 . All were significant at $p<.001$. Scores ranged from 25 to 175 with higher scores reflecting higher resilience. Scores greater than 145 indicated moderate to high resilience, scores within 121 to 145 indicated moderate to low levels of resilience, and scores of 120 and below indicated low resilience [35].

\subsection{Depression and Anxiety Stress Scale-21 (DASS-21) [36]}

The DASS-21 is a 21 -item measuring psychological distress consisting of three scales: depression, anxiety and stress. Although the three-factor structure of the DASS-21 has been supported in previous research, research has also indicated an overall level of psychological distress can be measured by calculating a total scale for the entire scale with acceptable psychometric properties [37]. For the purpose of the current study, a total scale score was utilised for analysis, providing a measure of psychological distress. Higher scores were indicative of greater psychological distress and low psychological well-being. Previous research has found the DASS-21 to be a valid and psychometrically sound instrument [36].

\section{Procedure}

Participants were randomly allocated into either a Control or Willpower Strengthening Group on the basis of an unpredictable, chance (random) process, using simple (unrestricted randomisation). The Willpower Strengthening Group was the active intervention group and carried out both exercises. The Five-Minute Willpower Exercise [31] instructed participants to focus on the inhaling and exhaling of their breath for five minutes. The Willpower Check-In Exercise involved participants stopping their present activities, adjusting their posture, and acknowledging their thoughts and emotions. Participants were tested across two laboratory sessions, separated by a time period of seven days. Figure 1 depicts the procedure for pre-test, which comprised of five phases. The third phase involved participants being randomly allocated into a group. The Control Group was instructed to leave the room while the Willpower Strengthening Group watched a brief instructional video.

Instructional videos were created by the researchers to enhance the understanding and procedure of each of the Willpower Strengthening Exercises. Individuals listened to the video instruction on separate computer screens, with headphones. The delivery of instructions was designed to support a range of learning styles to increase understanding and comprehension of the relevant exercises, and as well to increase compliance during intervention.

During the seven days between testing sessions, the Willpower Strengthening Group, were instructed to wear The Meaning to Pause ${ }^{\circledR}$ bracelet [39] for six hours a day. The bracelets were bought commercially and provided a gentle and discrete vibration every hour to remind participants to carry out the designated exercise. They were used to standardise how often participants practiced the 
willpower strengthening exercises, and improved upon Muraven and Colleagues [10] lack of standardisation. Researchers chose to use the Meaning to Pause ${ }^{\circledR}$ bracelets, as they were shown to be very feasible and non-intrusive for university students in previous research [39].

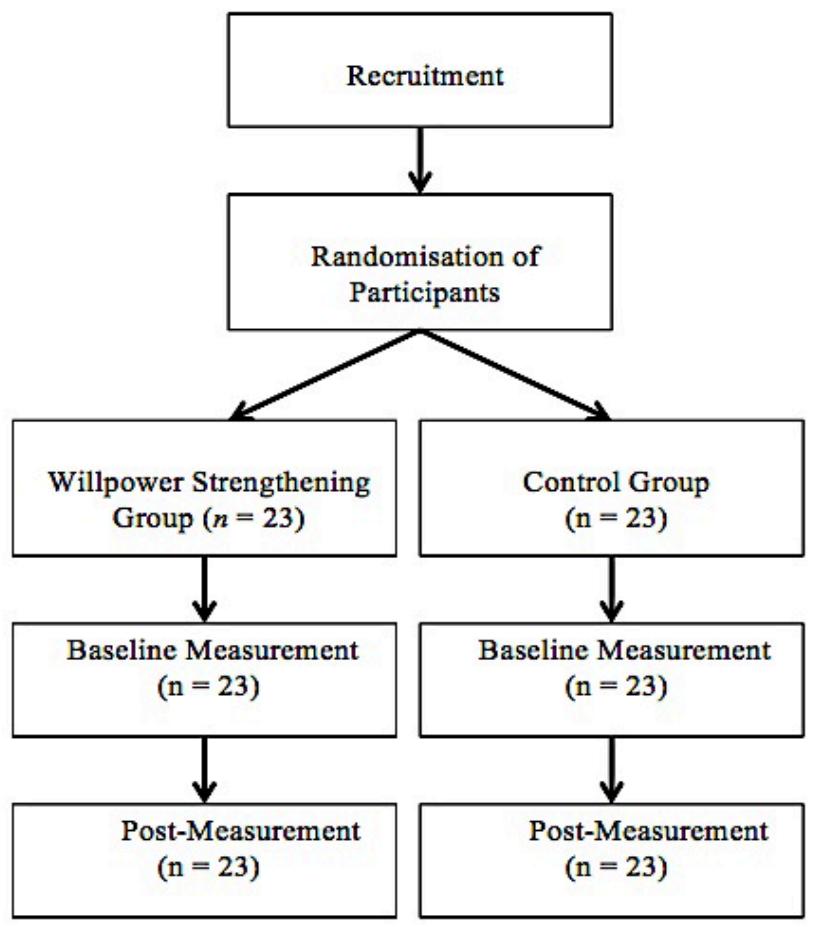

Figure 1. Schedule of research design and measurement for the willpower strengthening group and the control group. The sizes of the figure bear no weight or reflection on the type of task administered. They are only for visual effect.

Participants were instructed to keep a record of compliance to the Willpower Strengthening Exercises by completing a self-monitoring sheet. After the seven days, all participants returned for the post-test session, which was identical to the four phases of testing in the first laboratory session. All dependent variables were measured for a second time. Data was collected during the beginning of the university semester. To control for the potential confounding variable of exam stress, participants were not tested four week prior to university exams. The schedule of the research design and measurement of the Willpower Strengthening Group and Control Group is depicted in Figure 1.

\section{Design}

The study was a 2 x 2 (group type: Control vs. Willpower Strengthening) x 2 (time: pre-test and post-test) mixed methodological design. Participants were randomly allocated to either the Control Group, or an Intervention Group. The dependent variables were: Self-Control, Psychological Well-Being and Resilience. All variables were evaluated at pre-test and post-test. Each session took approximately 60 minutes. At the post-test participants were asked to give qualitative feedback about their experience of the Willpower Strengthening Exercises.

\section{Results}

Prior to analysis the data was screened and assumptions were met. Each of the 46 participants in this study was tested at pre-test and post-test. Participants in the two Intervention Group reported high compliance to the Willpower Strengthening Exercises over the seven days. All participants in the Intervention Group completed the self-monitoring forms, which showed adherence to performing the Willpower Strengthening Exercises 95\% - 100\% of the time during the intervention.

The high compliance and adherence rates support the hypothesis that the Willpower Strengthening Exercises were feasible for university students. Descriptive statistics for the means and standard deviations of the dependent variables for pre-test and post-test are presented in Table 1. The results indicate that the Willpower Strengthening Group had an increase in BSCS and RS scores, and a decrease in DASS-21 scores from pre-test to post-test.

Table 1. Means and Standard Deviations of Dependent Variables for Each Group Type

\begin{tabular}{|l|c|c|c|c|c|c|c|c|}
\hline & \multicolumn{2}{|c|}{ Control Group } & \multicolumn{6}{|c|}{ Willpower Strengthening Group } \\
\hline & \multicolumn{2}{|c|}{$\mathrm{T} 1$} & \multicolumn{2}{|c|}{$\mathrm{T} 2$} & \multicolumn{2}{|c|}{$\mathrm{T} 1$} & \multicolumn{2}{c|}{$\mathrm{T} 2$} \\
\hline Measure & $\mathrm{M}$ & $\mathrm{SD}$ & $\mathrm{M}$ & $\mathrm{SD}$ & $\mathrm{M}$ & $\mathrm{SD}$ & $\mathrm{M}$ & $\mathrm{SD}$ \\
\hline BSCS & 30.13 & 5.57 & 29.6 & 4.98 & 27.48 & 5.74 & 43.13 & 8.54 \\
\hline RS & 50.61 & 4.92 & 51.22 & 4.42 & 51.91 & 5.49 & 58.52 & 5.38 \\
\hline DASS-21 & 38.17 & 17.47 & 41.83 & 19.24 & 37.74 & 22.49 & 16 & 12.75 \\
\hline
\end{tabular}

Note. $\mathrm{T} 1$ = Pre-test; $\mathrm{T} 2=$ Post-test; $\mathrm{BSCS}=$ Brief Self-Control Scale; RS = Resilience Scale; DASS-21= Depression Anxiety Stress Scale 21

Multivariate analysis of variance (MANOVA): A Two-Way Repeated Measures MANOVA was conducted to investigate the interaction of within-subjects factors: time on the three between-subjects factors of self-control, resilience, and psychological distress. It was hypothesised that participants in the Willpower Strengthening Group would improve their self-control and resilience over time, and decrease psychological distress over time compared to the Control Group.

The multivariate test indicated a significant main effect between group and time, $F(3,42)=26.33, p<.001, \eta_{p}^{2}=.65$, power $=>1$, indicating that the three dependent variables, BSCS, RS, DASS-21 significantly varied from pre-test to post-test, as a function of the group type participants were assigned to. Likewise, the results indicated a significant main effect of group type, $F(3,42)=6.63 . p=.001, \eta_{p}^{2}=.32$, power $=.96$, suggesting that there was a significant variance in the dependent variables, as a function of the type of group participants were allocated to. These results supported Hypothesis 1.

The results did indicate a significant effect of time, $F(3,42)$ $=26.33, p<.001, \eta_{p}^{2}=.65$, power $=>1$. The dependent variables BSCS, RS, DASS-21 significantly differed between pre-test and post-test. This supported the hypothesis that scores would significantly change over time. Univariate 
tests revealed a significant main effect across time for self-control, $\left(F(1,44)=47.19, p<.001, \eta_{p}^{2}=.52\right.$, power $=>1)$. Univariate tests also revealed a significant main effect for resilience $\left(F(1,44)=15.89, p<.001, \eta_{p}^{2}=27\right.$, power $\left.=.97\right)$ and psychological distress $(F(1,44)=18.68, p<.001,=.29$, power $=.99)$. These results supported Hypothesis 1 .

The results indicated a significant effect of time, $F(3,42)$ $=26.33, p<.001, \eta_{p}^{2}=.65$, power $=>1$. These results indicated that the dependent variables BSCS, RS, DASS-21 changed significantly between pre-test and post-test. This supported the Hypothesis 1. Univariate tests revealed a significant main effect across time for self-control, $(F(1,44)$ $=47.19, p<.001, \eta_{x}^{2}=.52$, power $\left.=>1\right)$. Univariate tests also revealed a significant main effect for resilience $(F(1,44)=$ $15.89, p<.001, \eta_{p}^{2}=27$, power $\left.=.97\right)$ and psychological distress $\left(F(1,44)=18.68, p<.001, \eta_{p}^{2}=.29\right.$, power $\left.=.99\right)$.

Table 2. Univariate Tests of Dependent Variables Across Pre-test and Post-test

\begin{tabular}{|c|c|c|c|}
\hline Measure & $\mathrm{F}$ & $\eta_{p}^{2}$ & Power \\
\hline BSCS & $47.19^{* * *}$ & 0.52 & 1 \\
\hline RS & $15.89^{* * *}$ & 0.27 & 0.97 \\
\hline DASS-21 & $18.68^{* * *}$ & 0.29 & 0.99 \\
\hline
\end{tabular}

Note. $* p<.05, * * p<.01, * * * p<.001$

Due to results indicating a significant main effect for group and time, a split-plot MANOVA was conducted to further investigate the between-subjects effects of the group type on self-control, resilience, and psychological distress scores. A multivariate test indicated that for participants allocated to the Willpower Strengthening Group, there was a significant main effect of time, Wilks's $\Lambda=.127, F(3,20)=$ $45.65, p<.01, \eta_{p}^{2}=.87$, power $=>1$. Results of univariate tests demonstrated that students in the Willpower Strengthening Group, time had a significant effect on self-control scores, $F(1,22)=102.27, p=.001, \eta_{p}^{2}=.82$, power $=>1$. For students in the Willpower Strengthening Group, an increase was observed between the self-control pre-test measure ( $M=$ $27.48, S D=5.74)$ and self-control post-test measure $(\mathrm{M}=$ 43.13, $S D=8.54)$. These results supported Hypothesis 1 .

Results of a univariate test demonstrated that participants in the Willpower Strengthening Group, time had a significant effect on resilience scores, $F(1,22)=36.62, p<.001, \eta_{p}^{2}$ $=.63$, power $=>1$. For participants in the Willpower Strengthening Group, an increase was observed between the resilience pre-test measure $(M=51.91, S D=5.49)$ and resilience post-test measure $(M=58.52, S D=5.38)$. These results supported Hypothesis 1. Results of a univariate test demonstrated that participants in the Willpower Strengthening Group, times had a significant effect on psychological distress scores, $F(1,22)=39.52, p<.001, \quad \eta_{p}^{2}$ $=.64$, power $=>1$. For participants in the Willpower Strengthening Group, a decrease was observed between the psychological distress pre-test measure $(M=37.74, S D=$ $22.49)$ and post-test measure $(M=16.00, S D=12.75)$. These results supported Hypothesis 1 .

The split-plot MANPOVA further revealed that for students who were allocated in the Control Group, there was not a significant main effect of time, $F(3,20)=1.00, p=$ .412. Results of univariate tests demonstrated no significant effect for self-control, resilience, and psychological distress. These results supported Hypothesis 1, as over time no significant difference were observed for the Control Group across all measures at pre-test and post-test.

\section{Qualitative Analysis}

Data regarding feasibility of implementing willpower strengthening exercises with university students was obtained from qualitative feedback given by participants. Overall participants reported positive comments about the Willpower Check-In Exercise, for instance "The Willpower Check-In Exercise helped me to be aware of my thoughts and feelings, which in turn gave me a sense of control over myself and environment", "Gave me a constant reminder to refocus and clear my head". Participants also gave positive feedback about the Five-Minute Willpower Exercise, comments included, "I found this very relaxing, helped to reflect on myself emotionally, thought wise and physically", "reminded me to allow myself to take a break and catch up with myself." The feedback provides support for Hypothesis 2, as the Willpower Strengthening Exercises were able to easily fit into a busy university schedule.

\section{Conclusions}

The aim of this present study was to measure the effectiveness of Willpower Strengthening Exercises on self-control, resilience and psychological distress among university students. The prediction that the willpower strengthening group will report significantly higher levels of self-control and resilience, and significantly lower levels of psychological distress compared to the control group at post-intervention was supported. The results supported these findings from previous research by Muraven et al. [10] which indicated that postural adjustments, over a two-week period, increased self-control.

In addition, the findings from the current study also found that the Willpower Strengthening Group reported a significant increase post-intervention across the five domains of self-control, which include: emotional control, thought control, impulse control, performance regulation, and habit breaking [12].

In addition, the results from the current study supported the feasibility of willpower strengthening exercises with university students. Participants in the study reported performing the Willpower Strengthening Exercises 95-100\% of the time. This high compliance rate and positive feedback regarding performing the willpower strengthening exercises shows support for the feasibility of implementing brief intensive willpower strengthening exercises with university students.

The generalisability of the findings in this present study is 
limited due to the female gender bias of the sample. To the authors' knowledge this was the first study to implement and evaluate Willpower Strengthening Exercises over a seven-day period using a randomised control trial. In addition, this study addressed the limitations of previous studies, such as measuring self-control across five domains, which previous research had only focused on performance control [10].

The utilisation in this current study of Meaning to Pause ${ }^{\circledR}$ bracelets demonstrated an inventive use of new technology that had not been previously used in this field of research. Finally, the study had a $95-100 \%$ compliance rate with nil attrition, which may have been due to the short time frame. Researchers suggest that the high compliance rates may be attributable, in part, to the short and encouraging reminder emails sent to participants each morning during the intervention.

Due to the short time duration of the study meant that participants only required short times to perform the brief Willpower Strengthening Exercises designed to accommodate the demanding lifestyle of university students. The advantages of developing Willpower Strengthening Exercises for university students include increasing self-control, resilience, and decreasing psychological distress.

\section{REFERENCES}

[1] Arthur, N., \& Hiebert, B. (2011). Coping with transition to post-secondary education. Canadian Journal of Counselling and Psychotherapy/Revue canadienne de counseling et de psycho thérapie, $30(2)$.

[2] Australian Psychological Society. (2014). Stress and wellbeing in Australia Survey 2013. Retrieved from http;//www.psychology.org.au/Assets/Files/Stress\%20and\% 20wellbeing\%20\%20Australia\%20survey\%202012.pdf

[3] Machuca, J. R. (2010). Resilience characteristics of master's-level counseling students. (Doctoral Dissertation, University of New Orleans). Retrieved from http:/scholarworks.uno.edu/td/1272/

[4] Ahern, N. R., Kiehl, E. M., Sole, M. L., \& Byers, J. (2006). A review of instruments measuring resilience. Issues in Comprehensive Pediatric Nursing, 29, 103-125. doi: 10.1080/01460860600677643

[5] Tugade, M. M., Fredrickson, B. L., \& Feldman Barrett, L. (2004). Psychological resilience and positive emotional granularity: Examining the benefits of positive emotions on coping and health. Journal of personality, 72(6), 1161-1190

[6] Wills, T. A., \& Bantum, E. O. C. (2012). Social support, self-regulation, and resilience in two populations: General-population adolescents and adult cancer survivors. Journal of Social and Clinical Psychology, 31(6), 568-592.

[7] Baumeister, R. F., Vohs, K. D., \& Tice, D. M. (2007). The strength model of self-control. Current directions in psychological science, 16(6), 351-355. doi:10.1111/j.1467-8721.2007.00534.x

[8] Baumeister, R. F., Gailliot, M., DeWall, C. N., \& Oaten, M. (2006). Self-Regulation and Personality: How Interventions Increase Regulatory Success, and How Depletion Moderates the Effects of Traits on Behavior. Journal of personality, 74(6), 1773-1802.

[9] Wagnild, G. M., \& Young, H. M. (1993). Development and psychometric evaluation of the Resilience Scale. Journal of Nursing Measurement. Retrieved from

http://www.sapibg.org/attachments/article/1054/wagnild_19 93 resilience scale 2

[10] Muraven, M., Tice, D. M., \& Baumeister, R. F. (1998). Self-control as a limited resource: Regulatory depletion patterns. Journal of personality and social psychology, 74(3), 774 .

[11] Baumeister, R. F., Heatherton, T. F., \& Tice, D. M. (1994). Losing control: How and why people fail at self-regulation. Academic Press.

[12] Ayduk, O., Mendoza-Denton, R., Mischel, W., Downey, G., Peake, P. K., \& Rodriguez, M. (2000). Regulating the interpersonal self: strategic self-regulation for coping with rejection sensitivity. Journal of personality and social psychology, 79(5), 776-792.

[13] Mischel, W., Ayduk, O., Berman, M. G., Casey, B. J., Gotlib, I. H., Jonides, J., \& Shoda, Y. (2010). 'Willpower' over the life span: decomposing self-regulation. Social Cognitive and Affective Neuroscience, 1-5. doi:10.1093/scan/nsq081

[14] Mischel, W., Ebbesen, E. B., \& Raskoff Zeiss, A. (1972). Cognitive and attentional mechanisms in delay of gratification. Journal of personality and social psychology, 21(2), 204.

[15] Wong, J. G., Cheung, E. P., Chan, K. K., Ma, K. K., \& Wa Tang, S. (2006). Web-based survey of depression, anxiety and stress in first-year tertiary education students in Hong Kong. Australian and New Zealand Journal of Psychiatry, 40(9), 777-782.

[16] Byrd, D. R., \& McKinney, K. J. (2012). Individual, interpersonal, and institutional level factors associated with the mental health of college students. Journal of American College Health, 60, 185-193. doi:10.1080/07448481.2011.584334

[17] Storrie, K., Ahern, K., \& Tuckett, A. (2010). A systematic review: students with mental health problems - a growing problem. International journal of nursing practice, 16(1), 16.

[18] DeRosier, M., Frank, E., Schwartz, V., \& Leary, K. (2013). The potential role of resilience education for preventing mental health problems for college students. Psychiatric Annals, 43, 538-544. doi:10.3928/00485713-20131206-05

[19] Baumeister, R. F., \& Tierney, J. (2011). Willpower: Rediscovering the greatest human strength. Penguin.

[20] Carver, C. S., \& Scheier, M. F. (1998). On the Self-Regulation of Behavior. New York: Cambridge University Press.

[21] Gross, J. J., \& John, O. P. (2003). Individual differences in two emotion regulation processes: implications for affect, relationships, and well-being. Journal of personality and 
social psychology, 85(2), 348.

[22] Tugade, M. M., Fredrickson, B. L., \& Feldman Barrett, L. (2004). Psychological resilience and positive emotional granularity: Examining the benefits of positive emotions on coping and health. Journal of personality, 72(6), 1161-1190.

[23] Freud, S. (1961). Neurosis and psychosis. In The Standard Edition of the Complete Psychological Works of Sigmund Freud, Volume XIX (1923-1925): The Ego and the Id and Other Works (pp. 147-154).

[24] Baumeister, R. F., Bratslavsky, E., Muraven, M., \& Tice, D. M. (1998). Ego depletion: is the active self a limited resource? Journal of personality and social psychology, 74(5), 12521265

[25] Wegner, D. M., Schneider, D. J., Carter, S. R., \& White, T. L. (1987). Paradoxical effects of thought suppression. Journal of personality and social psychology, 53(1), 5-7.

[26] Baumeister, R. F., Heatherton, T. F., \& Tice, D. M. (1994). Losing control: How and why people fail at self-regulation. Academic Press.

[27] Oaten, M., \& Cheng, K. (2006). Improved self-control: The benefits of a regular program of academic study. Basic and Applied Social Psychology, 28(1), 1-16.

[28] Oaten, M., \& Cheng, K. (2006). Longitudinal gains in selfregulation from regular physical exercise. British journal of health psychology, 11(4), 717-733.

[29] Masicampo, E. J., \& Baumeister, R. F. (2008). Toward a physiology of dual-process reasoning and judgment: Lemonade, willpower, and expensive rule-based analysis. Psychological Science, 19(3), 255-260.

[30] McGonigal, K. (2011). The Willpower Instinct: How Self-Control Works, Why It Matters, and What You Can do to Get More of It. Penguin.

[31] Tangney, J. P., Baumeister, R. F., \& Boone, A. L. (2004). High self-control predicts good adjustment, less pathology, better grades, and interpersonal success. Journal of personality, 72(2), 271-324.

[32] Tabachnick, B. G., Fidell, L. S., \& Osterlind, S. J. (2001). Using multivariate statistics (5th ed.). New York: Allyn and Bacon.

[33] Plake, B. S., Impara, J. C., \& Spies, R. A. (2003). The 15th mental measurements yearbook. Lincoln, NE: Buros Institute of Mental Measurements.

[34] Wagnild, G. M., \& Young, H. M. (1993). Development and psychometric evaluation of the Resilience Scale. Journal of Nursing Measurement. Retrieved from http://www.sapibg.org/attachments/article/1054/wagnild_19 93 resilience scale 2

[35] Lovibond, S. H., \& Lovibond, P. F. (1995). Manual for the Depression Anxiety Stress Scales (2nd ed.). Sydney, NSW: Psychology Foundation.

[36] Henry, J. D., \& Crawford, J. R. (2005). The short-form version of the Depression Anxiety Stress Scales (DASS-21): Construct validity and normative data in a large non-clinical sample. British Journal of Clinical Psychology, 44(2), 227239.

[37] Henry, J. D., \& Crawford, J. R. (2005). The short form version of the depression anxiety stress scales (DASS-21): Construct validity and normative data in a large non-clinical sample. The British Journal of Clinical Psychology, 44, 227. doi: 10.1348/014466505X29657

[38] Graham, C., \& Irish, K. (2010). Meaning to pause. http://www.meaningtopause.com

[39] Pidgeon, A. M., \& Monteath, S. L. (2013). Feasibility and efficacy of willpower strengthening exercises with University students: A randomised control pilot study. Open Journal of Social Sciences, 1(06), 5-11. 